rings, being really much smaller than the apparent size due to physiological effects, and of this latter size every star must appear.

The accompanying woodcuts of a region in the constellation of Gemini as seen with the naked eye and with a powerful telescope will give a better idea than mere language can do of the effect of this so-called spacepenetrating power.

With nebulæ and comets matters are different, for these, even with small telescopes and low powers, often occupy an appreciable space on the retina. On increasing the aperture we must also increase the power of the eyepiece, in order that the more divergent cones of light from each point of the image shall enter the pupil, and therefore increase the area on the retina, over which the increased amount of light, due to greater aperture, is spread; the brightness, therefore, is not increased, unless indeed we were at the first using an unnecessary high power. On the other hand, if we lengthen the focus of the object-glass and increase its aperture the divergence of the cones of light is not increased and the eye-piece need not be altered, but the image at the focus of the object-glass is increased in size by the increase of focal lengtb, and the image on the retina also increases as in the last case. We may therefore conclude that no comet or nebula of appreciable diameter, as seen through a telescope having an eye-piece of just such a focal length as to admit all the rays to the eye, can be made brighter by any increase of power, although it may easily be made to appear larger.

Very beautiful drawings of the nebula of Orion and of other nebulæ, as seen by Lord Rosse in his 6-foot reflector, and by the American astronomers with their 26-inch refractor, have been given to the world.

The magnificent nebula of Orion is scarcely visible to the naked eye ; one can just see it glimmering on a fine night; but when a powerful telescope is used it is by far the most glorious object of its class in the northern fiemisphere, and surpassed only by that surrounding the variable star $\eta$ Argûs in the southern. And although, of course, the beauty and vastness of this stupendous and remote object increase with the increased power of the instrument brought to bear upon it, a large aperture is not needed to render it a most impressive and aweinspiring object to the beholder. In an ordinary 5-foot achromatic many of its details are to be seen under favourable atmospheric conditions.

Those who are desirous of studying its appearance, as seen in the most powerful telescopes, are referred to the plate in Sir John Herschel's "Results of Astronomical Observations at the Cape of Good Hope," in which all its features are admirably delineated, and the positions of I50 stars which surround $\theta$ in the area occupied by the nebula laid down. In Fig. 4 it is represented in great detail, as seen with the included small stars, all of which have been mapped with reference to their positions and brightness. This, then, comes from that power of the telescope which simply makes it a sort of large eye. We may measure the illuminating power of the telescope by a reference to the size of our own eye. If one takes the pupil of an ordinary eye to be something like the fifth of an inch in diameter, which in some cases is an extreme estimate we shall find that its area would be roughly about one-thirtieth part of an inch. If we take Lord Rosse's speculum of six feet in diameter the area will be something like 4,000 inches; and if we multiply the two together we shall find, if we lose no light, we should get I20,000 times more light from Lord Rosse's telescope than we do from our unaided eye, everything supposed perfect.

Let us consider for a moment what this means; let us take a case in point. Suppose that owing to imperfections in reflection and other matters two-thirds of the light is lost so that the eye receives 40,000 times the amount given by the unaided vision, then a sixth magnitude stara star just visible to the naked eye-would have 40,000 times more light, and it might be removed to a distance 200 times as great as it at present is and still be visible in the field of the telescope just as it at present is to the unaided eye. Can we judge how far off the stars are that are only just visible with Lord Rosse's instrument? Light travels at the rate of 185,000 miles a second, and from the nearest star it takes some $3 \frac{1}{2}$ years for light to reach us, and we shall be within bounds when we say that it will take light 300 years to reach us from many a sixth magnitude star.

But we may remove this star 200 times further away and yet see it with the telescope, so that we can probably see stars so far off that light takes 60,000 years to reach us, and when we gaze at the heavens at night we are viewing the stars not as they are at that moment, but as they were years or even hundreds of years ago, and when we call to our assistance the telescope the years become thousands and tens of thousands-expressed in miles these distances become too great for the imagination to grasp; yet we actually look into this vast abyss of space and see the laws of gravitation holding good there, and calculate the orbit of one star about another.

(To be continued.)

J. NORMAN LOCKYER

\section{ZOOLOGICAL GARDENS 1}

THE lists and reports of the various zoological gardens now before us show that much progress has lately been made by these as by other institutions connected with natural history. For though zoological gardens are looked upon by many as a simple form of amusement there can be no question that, when rightly conducted, they are not only instructive in the highest degree, but also tend materially to advance the interests of the higher branches of natural science. All persons, therefore, who take an interest in the progress of science will be glad to see the number of zoological gardens increasing among the dependencies of this country and in other States.

Of the first of the five works on our list we need say but little. The Gardens of the Zoological Society of London, in the Regent's Park, are too well known to most of our readers to require a lengthened notice. The chief additions to their unrivalled menagerie are recorded every week in our columns. The volume now before us contains a catalogue of all the species of vertebrated animals, of which examples have been exhibited during the past fifteen years, arranged in systematic order. The various specimens are distinguished by letters, and the date and mode of acquisition of each individual are added. Thirty-five woodcuts, most of which have originally appeared in the Society's Proceedings, illustrate some of the more remarkable forms. The result shows that from the commencement of the year I86I to the close of 1875 , there have been obtained for the collection in the Regent's Park, examples of no less than 2, I 43 species of vertebrated' animals. Of these 570 were mammals, 1,224 birds, 227 reptiles, 39 batrachians, and 83 fishes.

The catalogue of the animals in the newly-established Zoological Gardens at Calcutta, concerning the foundation and progress of which we have written at full length not long since, ${ }^{2}$ is next upon our list. It is drawn up after ${ }^{I}$ ( $\mathrm{r}$ List of Vertebrated Animals now or lately living in the Gardens of the Zoological Society of London. Sixth Edition. 1877. (London:
Longmans).

(2) List of Vertebrated Animals living in the Zoological Gardens, Calcutta (2) List of Vertebrated Animals living in the Zoological Gardens,
April, 1877 . Printed at the Bengal Secretarial Pres: 1877. 8vo.

(3) A Guide to the Peoples Park, Madras, with a description of the Zoological Collection contained theren. (Madras : Higginbotham and Co.,

(4) The Fifth Annual Report of the Board of Directors of the Zoological Society of Philadelphia. Kead at the Annual Meeting of the Members and Loanholders of the Society, A pril 26, 1877 . 8vo. (Philadeiphia, 1877 )

(5) Report of the Director of the Central Yark Menagrrie, Department of Public Parks, City of New York, for year 1876 . (New York, 1877: B. M. Nature, vol, xvi. p. 28.
inter 
the fashion of the preceding, and has been prepared by Dr. John Anderson, the Superintendent of the Imperial Museum at Calcutta. It shows that though so recently in actual operation these gardens have already made considerable progress, and are able to show a good series of the better-known Indian animals for the instruction and amusement of the Calcutta public. Amongst others we may notice the Indian Otter (Lutra leptonyx) and the Isabelline Bear, as animals which have not yet reached the Gardens of the Zoological Society of London. Altogether there are 77 species of mammals in the collection, 120 of birds, and 17 of reptiles.

The "Guide to the People's Park" shows that Madras does not intend to be left behind the sister-city of Calcutta, and that she too will have a zoological garden. As its name imports, this little work is more of the nature of a "Guide" than a Catalogue. It appears that Madras is indebted to Sir Charles Trevelyan for the People's Park. Prior to 1859 the plot of ground which it now occupies formed "an immense swamp." In that year the enlightened governor of the day first suggested, and subsequently put into execution, the conversion of it into a park of about II6 English acres. (How glad would be the Council of the Zoological Society of London to have such an area at their disposal !) The collection of animals does not yet, it is true, appear to be very extensive ; but space, at any rate, does not fail them, and there is, at all events, plenty of roorn for additions, which cannot be said of some of the sister institutions.

We must now turn to the western hemisphere, and see what our Anglo-Saxon relatives on the other side of the Atlantic have done in the way of zoological gardens. In this matter, we must say, our usually energetic cousins seem to have moved a little slowly. Such vast and wealthy populations as those of New York and Philadelphia might well have started zoological gardens for the instruction and amusement of their citizens years ago, and they would by this have been in possession of wellorsanised institutions. But although the subject has been mooted in both these cities for many years, it is only within these last few years, we believe, that anything very practical has been effected.

The Zoological Garden of New York forms a part of the Central Park of that city, and the report now before us is addressed by Mr. W. A. Conklin, the director, to the Board of Commissioners of the Department of Public Parks of New York. It gives us an account of the affairs of the Zoological Garden during the year 1876 , and not apparently a very satisfactory one-since a reduction of the sum usually appropriated (by the City of New York, we presume) to the Park was made that year, which rendered it impossible to keep up the Gardens on their usual footing. It was resolved " not to receive any animal for exhibition in the menagerie unless the owner furnished the necessary food." This measure and the diminution of the sum expended in new purchases seem to have caused a sad decrease in the number of animals exhibited in 1876 . In spite of this the number of visitors was larger than in any previous year, which, however, is accounted for by the concourse of visitors passing through New York to and from the Centennial Exhibition at Philadelphia.

While the Zoological Garden of New York is kept up out of public moneys that at Philadelphia is, like ours in London, the property of a private society, and appears to be in a much more flourishing condition. Here the "Centennial" told still more largely on the number of visitors than at New York, raising them to a grand total of more than 600,000 for the year ending April 30 last. The extra receipts from this source have not only enabled the society to make many important additions to its menagerie, but also to spend a considerable sum in improvements and new buildings. Amongst the latter we notice "a house for the accommodation of warm-climated (!) hay-eating animals" (qu, zebras and antelopes ?) now under construction at an estimated cost of I 8,000 dollars, which will apparently exceed in dimensions even the new lion-house of the Zoological Society of London. This is pretty well for a society only now issuing its ffth annual report. It is evident that in zoological gardens, as in other scientific institutions, Philadelphia means to "go-ahead" of her more populous neigh bour.

\section{NOTES}

WE take the following from the Times:-The Royal Society medals for the present year have been awarded by the President and the Council as follows:-The Copley Medal to Prof. James Dwight Dana, for his biological, geological, and mineralogical investigations, carried on through half a century, and for the valuable works in which his conclusions and discoveries have been published. A Royal Medal to Mr. Frederick Augustus Abel, F.R.S., for his physico-chemical researches on gun-cotton and explosive agents. A Royal Medal to Prof. Oswald Heer, of Zurich, for his numerous researches and writings on the tertiary plants of Europe, of the North Atlantic, North Asia, and North America, and for his able generalisations respecting their affnities and their geological and climatic relations; and the Davy Medal to Robert Wilhelm Bunsen and Gustav Robert Kirchhoff, for their researches and discoveries in spectrum analysis. This is the first award of the Davy medal, which, as will be remembered, was founded by the proceeds of the sale of the service of silver plate bequeathed for the purpose by Sir Humphry Davy. The medals will be presented at the Society's anniversary meeting on the 30 th inst.

A EEW days ago the French Minister of Public Instruction, by a decree which has not yet been published, appointed a Commission to deliberate with the members of the council of the Observatory of Paris, as to the improvements which are pos. sible in the organisation of the establishment without interfering with existing decrees. Among the commissioners are Dr. Janssen, Director of the Meudon Physical Observatory, $M$. Hervé Mangon, President of the Meteorological Society of France, and M. Marie Davy, the Director of the Montsouris Observatory. M. Yyon Villarceau and M. Loewy have been appointed as councillors. The first meeting of the Commission took place last Saturday, under the presidency of M. Dumesnil, one of the heads of the ministry, representing M. Brunet. M. Yvon Villarceau, the astronomer delegate, read a long and elaborate report on the improvements which it was considered desirable to make in the establishment. The Commission came to no decision, and the meeting adjourned to Saturday, Dec. $\mathrm{r}$. Some of the members are desirous of separating the meteoro. logical department from the observatory, and either transfer it to Montsouris or establish a Meteorological Institute; to accom. plish this long desired change it would be necessary to suppress the decrees signed by M. Thiers, and approved by M. Leverrier. The intentions of the Government are not to alter radicaliy the existing state of things, which works satisfactorily, but to improve it as far as possible. Public opinion is strongly in favour of the organisation consecrated by $M$. Leverrier's administration.

Two volumes of the French Transit of Venus Reports are now going through the press, and will be distributed in a very few days. The first is a compte rendu of the mission in China, commanded by Capt. Fleurian. The second is a procès verbal of the sittings of the Transit Commission, which was presided over by M. Dumas. It is known that M. Leverrier abstained from being present at its deliberations, the illustrious astronomer being one of the few opponents of the transit observation. He preferred the opposition of Mars or direct measurements as taken by Cornu in his experiments on the velocity of light.

Tre French Government intends to send out an expedition to San Francisco in order to observe the next transit of Mercury, which will take place on May $6, x 878$. 